\title{
SEMENTE DE MILHO SOB COMPRESSÃO DO SOLO E PROFUNDIDADE DE SEMEADURA: INFLUÊNCIA NO ÍNDICE DE VELOCIDADE DE EMERGÊNCIA ${ }^{1}$
}

\author{
CORN SEED UNDER SOIL COMPRESSION AND DEEP SEEDLING: \\ INFLUENCE ON THE EMERGENCE SPEED INDEX
}

\author{
Renato de Mello PRADO ${ }^{2}$ \\ José Luís TORRES ${ }^{3}$ \\ Cassiano Garcia ROQUE ${ }^{3}$ \\ Osvaldo COAN ${ }^{4}$
}

\begin{abstract}
RESUMO
O nível de compressão no leito da semeadura e a profundidade podem interferir na velocidade de emergência das plântulas, conseqüentemente, no estabelecimento inicial de plantas de milho. O presente estudo objetivou analisar a influência da compressão do solo associado com a profundidade de semeadura sobre o índice de velocidade de emergência e a sua relação com o crescimento inicial da cultura do milho. Para isso instalou-se um experimento na Faculdade de Ciências Agrárias e Veterinárias da UNESP, Campus de Jaboticabal, no período de abril a junho de 1999, em um Latossolo Vermelho. O delineamento experimental utilizado foi o inteiramente casualizado, com três repetições. Os tratamentos constaram da compressão do solo nos níveis 0 (testemunha), 5, 10 e $15 \mathrm{kgf}$, atingindo em média uma resistência à penetração no solo de 1,91, 3,39, 3,93 e 4,43 Mpa, respectivamente, e a profundidade de semeadura nos níveis 3,5 e $7 \mathrm{~cm}$. Avaliou-se, semanalmente, o índice de velocidade de emergência e a altura da planta de milho até 60 dias após a semeadura. Os resultados mostraram que para o estabelecimento inicial das plantas de milho a resposta foi linear para o índice de velocidade de emergência e para a altura de plantas a compressão do solo variou de 5 a $15 \mathrm{kgf}$ na roda compactadora de semeadura, sem restrições para profundidade de semeadura dentro da faixa de 3 a $7 \mathrm{~cm}$.

Palavras-chave: semeadora, roda compactadora, vigor, germinação, estande.
\end{abstract}

\begin{abstract}
The levels of soil depth and soil compactation on the seed affecting the seedlings speed emergence, consequently, the initial maize plants stablishment. With the objective to study the influence of sowing depth and soil compactation on the seed of a initial established maize crop, an experiment was conducted at the Faculdade de Ciências Agrárias e Veterinárias / UNESP, Jaboticabal, SP, from April to June, 1999, in haplustox. A completely randomized desing was used with three replications. The treatments of the soil compactation in four levels: 0 (control), 5, 10 and $15 \mathrm{kgf}$ corresponding to a resistence to penetration of 1.91, 3.39, 3.93 and $4.43 \mathrm{Mpa}$, respectively, and depths sowed in three levels: 3, 5 and $7 \mathrm{~cm}$. Emergence speed rate (ESR) and plant height were evaluated weekly during the first 60 days. The results showed that to initial established maize plants the answers were linear form to emergence speed rate and the plant height to a soil compactation varied betwen 5 to $15 \mathrm{kgf}$ achieved by compacting wheel, no restriction at a sowing depth of 3 to $7 \mathrm{~cm}$.
\end{abstract}

Key words: sowed, compacting wheel, fouce, germination, stand.

\footnotetext{
1 Trabalho apresentado no II Simpósio de Ciências Aplicadas da Associação Cultural de Garça, 14 a 16 OUT 1999, Garça, SP.

2 Engenheiro Agrônomo, Doutorando, Universidade Paulista Júlio de Mesquita Filho / Faculdade de Ciências Agrárias e Veterinárias de Jaboticabal, Departamento de Solos e Adubos, Via de Acesso Professor Paulo Donato Castellane, s/n CEP14870-000, Jaboticabal, SP. E-mail: rmprado@tcav.unesp.br $\equiv$ Autor para correspondência.

3 Engenheiro Agrônomo, Doutorando, Universidade Paulista Júlio de Mesquita Filho / Faculdade de Ciências Agrárias e Veterinárias de Jaboticabal, Departamento de Solos, Jaboticabal, SP.

${ }^{4}$ Engenheiro Agrônomo, Doutor, Universidade Paulista Júlio de Mesquita Filho / Faculdade de Ciências Agrárias e Veterinárias de Jaboticabal, Departamento de Engenharia Agrícola, Jaboticabal, SP.
} 


\section{INTRODUÇÃO}

Historicamente o milho sempre representou a principal cultura da agricultura brasileira, não somente no aspecto quantitativo, como também no que diz respeito a sua importância estratégica por ser a base da alimentação animal e, conseqüentemente, humana [1]. O Brasil é o terceiro maior produtor mundial de milho, depois do EUA e da China.

Apesar da importância da cultura do milho, o Brasil apresenta baixa produtividade, se comparada com países como EUA, Canadá e França. As principais causas da baixa produtividade são, entre outras, a ocorrência de plantas daninhas, a utilização inadequada de adubos e a baixa densidade de plantas [16]. A baixa densidade de plantas pode resultar em estande inadequado, para híbridos de milho de exigência específica. A baixa densidade de plantas ocorre em razão de problemas com a época da semeadura, seja pelo uso de um número inadequado de sementes ou pelo contato insuficiente solo-semente, que normalmente implica em pouca uniformidade da cultura do milho, fato que tem sido observado no estabelecimento de lavouras, mesmo quando se utiliza semente de alto poder germinativo. Portanto, um dos fatores que contribui diretamente para a obtenção de estande adequado ao estabelecimento da cultura do milho é a própria semeadora, no tocante à roda compactadora. Os poucos trabalhos que tratam dos efeitos da compressão do solo no leito de semeadura, na emergência e no crescimento das plantas, são contraditórios e revelam tanto efeitos positivos [3, 14] quanto negativos [8], em relação ao vigor inicial da lavoura. Em solos argilosos as sementes devem ser colocadas mais superficialmente, entre 3 e $5 \mathrm{~cm}$. Caso essas sementes sejam semeadas em maior profundidade, podem causar prejuízos à emergência das plântulas [4]. Isso decorre do maior gasto de energia da plântula na emergência, com reflexos no vigor inicial da cultura.

Assim, testou-se a hipótese de que tanto o nível de compressão do solo sobre a semente quanto a profundidade de semeadura podem interferir no crescimento inicial das plantas de milho, de maneira que o presente trabalho teve por objetivo avaliar os efeitos de compressão do solo e profundidade de semeadura no índice de velocidade de emergência e na altura de plantas de milho, até sessenta dias após a semeadura.

\section{METODOLOGIA}

Foi instalado um experimento na UNESPCampus de Jaboticabal, no período de abril a junho de 1999, nas coordenadas 48¹8'58' de longitude Oeste e 21015'22" de latitude Sul e altitude de $575 \mathrm{~m}$. O solo é classificado como um Latossolo Vermelho, classe textural argilosa (55\% de argila; $9 \%$ silte e $36 \%$ de areia). A pista do experimento constou basicamente de três faixas de solo de
$1,40 \mathrm{~m}$ por $24,00 \mathrm{~m}$, contendo quatro trilhos no sentido leste-oeste, sobre os quais deslocou-se um carrinho movimentado por sistema eletromecânico. A pista foi preparada por meio de um micro-trator com enxada rotativa, mobilizando o solo até $15 \mathrm{~cm}$ de profundidade e posteriormente nivelando.

A adubação de manutenção constou de $250 \mathrm{~kg} \cdot \mathrm{ha}^{-1}$ da fórmula 8-30-20 aplicada a lanço e incorporada. A adubação de cobertura foi feita com $20 \mathrm{~kg}, \mathrm{ha}^{-1}$ de N, na forma de uréia, aos 42 dias após a semeadura.

O delineamento experimental foi 0 inteiramente ao acaso, com três repetições, num esquema fatorial $4 \times 3$. O fator compressão do solo constou dos níveis: 5,10 e $15 \mathrm{kgf}$, além da testemunha sem compressão. $O$ fator profundidade de semeadura teve os níveis: 3,5 e $7 \mathrm{~cm}$. Cada parcela constou de três linhas espaçadas de $0,50 \mathrm{~m}$ e com 2,5 m de comprimento, sendo $0,25 \mathrm{~m}$ de cada lado da parcela considerado como bordadura.

Inicialmente, realizou-se a sulcação mecânica, com auxílio dos carrinhos, nos respectivos níveis de profundidade e, em seguida, foi realizada a semeadura do milho, manualmente, em 01/04/1999, com auxílio de tábuas, com orifício de $1 \mathrm{~cm}$ de diâmetro, eqüidistantes de $10 \mathrm{~cm}$, com duas sementes por cova, totalizando 15 covas por linha. Em seguida as sementes foram cobertas, manualmente, nivelando o solo, quando então o realizou-se a irrigação por aspersão, por meio de um tubo fixado no carrinho, atingindo a umidade média de $0,184 \mathrm{~kg} \cdot \mathrm{kg}^{-1}$, na profundidade de $0-30 \mathrm{~cm}$, determinada pelo método gravimétrico. A compactação foi realizada com a roda metálica cilíndrica, com $40 \mathrm{~cm}$ de diâmetro e $10 \mathrm{~cm}$ de largura, vinculada ao carrinho por meio de um suporte com eixo vertical deslizante, deslocando-se a $0,37 \mathrm{~m} \cdot \mathrm{s}^{-1}$, com as respectivas cargas dos tratamentos, colocadas sobre o eixo da roda.

Para melhor avaliar os níveis de compressão do solo em torno da semente, em função dos tratamentos, foi analisada a resistência mecânica à penetração, com um minipenetrômetro na linha da semeadura, a 0-5 e 5-10 cm de profundidade.

A irrigação, após a instalação da cultura, seguiu um turno de rega de dois dias, repondo a água da evapotranspiração, com o objetivo de manter a umidade do solo em $70 \%$ da capacidade de campo, até o final do ciclo da cultura. Aos 19 dias após a semeadura realizou-se o desbaste de plantas deixando uma por cova ou 15 por linha. Utilizou-se uma tesoura cortando-se as plantas no nível do colo, evitando-se perturbação física do solo.

O controle da lagarta do cartucho (Spodoptera frugiperda) foi realizado com pulverizações com inseticida (Decis $25 \mathrm{CE}$ ) na dose de 0,15 L.ha ${ }^{-1}$ do ingrediente ativo. Enquanto que o controle de plantas daninhas foi feito com aplicação localizada de herbicida (Roundup), na dose de 1,0 L.ha ${ }^{-1}$ do ingrediente ativo.

Avaliou-se a velocidade de emergência representada pelo índice de velocidade de emergência (IVE), conforme a metodologia de Nakagawa (1994)[11]. As leituras das plantas 
emergidas foram realizadas diariamente entre 7 e 18 dias após a semeadura, até que o número de plantas emergidas se apresentasse constante. Avaliou-se, também, o crescimento da planta representado pela altura média, que foi medida semanalmente, de 25 a 60 dias após a semeadura.

Os resultados obtidos foram submetidos à análise de variância. Nos casos em que foram detectados valores significativos pelo teste "F", foram realizados estudos de regressão polinomial. As relações estudadas foram compressão do solo versus resistência mecânica, compressão do solo versus IVE e IVE versus altura da planta.

\section{RESULTADOS E DISCUSSÃO}

Pelos resultados obtidos, quanto ao efeito da compressão do solo na resistência mecânica à penetração, observou-se relação funcional significativa entre essas variáveis, considerando que o aumento da compressão do solo levou a maior resistência do solo à penetração, explicada pelo efeito linear na camada de $0-5 \mathrm{~cm}$, como na camada de $5-10 \mathrm{~cm}$ de profundidade (Figura 1). Esses resultados indicam a resistência mecânica à penetração do solo em torno da semente, em função da aplicação dos tratamentos.

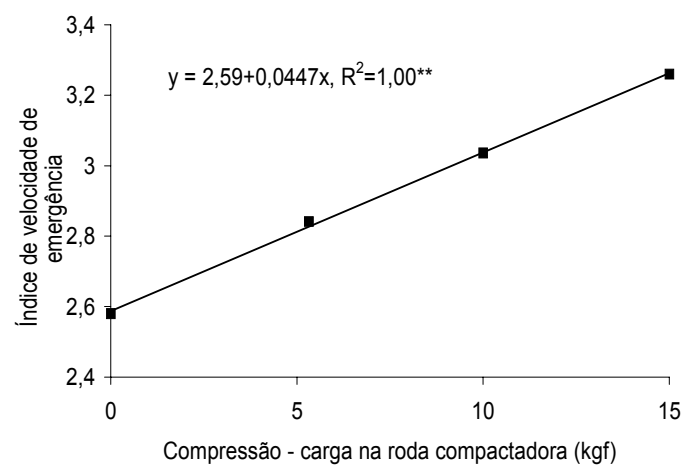

FIGURA 1 - Efeito da carga na roda compactadora sobre o índice de velocidade de emergência, Jaboticabal, SP, 1999

Pelos resultados da análise de variância do IVE (Tabela 1), observa-se que houve diferença significativa entre os níveis de compressão do solo, porém, não ocorreram interações significativas para profundidade de semeadura e nível de compressão do solo. A falta de interação indica que os fatores compressão do solo e profundidade de semeadura agem independentemente no IVE, para a cultura do milho.

Observou-se que à medida que aumentou o nível de compressão do solo ocorreu incremento linear no índice de velocidade de emergência, de modo que uma carga de $15 \mathrm{kgf}$ na roda compactadora refletiu em maior vigor da plântula e que a semeadura do milho, sem compressão do solo, representou o menor IVE (Figura 1). Esses resultados estão de acordo com Larson [10], que observou que a baixa compressão do solo ao redor da semente interferiu na germinação e no desenvolvimento inicial do milho, que foram mais lentos e explicou que isso deve ter ocorrido pela reduzida taxa de transmissão de água e nutrientes pela interface solo/semente/raiz.

TABELA 1 - Índice de velocidade de emergência (IVE) das plantas de milho em função da compressão do solo e da profundidade de semeadura, Jaboticabal, SP, 1999

\begin{tabular}{cc}
\hline Compressão (C) & IVE \\
\hline $4(15 \mathrm{kgf})$ & 3,3 \\
$3(10 \mathrm{kgf})$ & 3,0 \\
$2(5 \mathrm{kgf})$ & 2,8 \\
1 (testemunha) & 2,6 \\
\hline F de C & $5,20^{*}$ \\
\hline
\end{tabular}

Profundidade $(\mathrm{P})$

\begin{tabular}{cc}
\hline $2(5 \mathrm{~cm})$ & 3,0 \\
$3(7 \mathrm{~cm})$ & 3,0 \\
$1(3 \mathrm{~cm})$ & 2,8 \\
\hline $\mathrm{F}$ de P & $1,40^{\mathrm{ns}}$ \\
\hline $\mathrm{F}$ de C x P & $0,86^{\mathrm{ns}}$ \\
\hline Coeficiente de Variação $(\%)$ & 13,0
\end{tabular}

* Significativo a $5 \%$ de probabilidade pelo teste de $\mathrm{F}$

ns Não significativo pelo teste de $\mathrm{F}$

Os resultados para os níveis de compressão 10 e $15 \mathrm{kgf}$, para a camada de 5 a $10 \mathrm{~cm}$ de profundidade, atingiram resistência à penetração do solo equivalentes a 4,2 e 4,9 Mpa, respectivamente (Figura 2). Esses resultados estão em desacordo com Veen e Bonne (1990) [15] que relatam que o crescimento inicial do milho, em solo que apresenta resistência à penetração do solo de 4,2 Mpa, em torno da semente, fica completamente inibido.

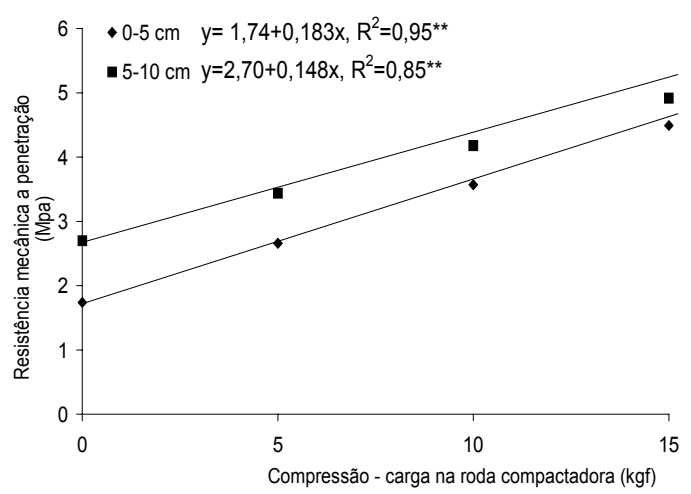

FIGURA 2 - Efeito da carga na roda compactadora sobre a semente na resistência mecânica à penetração, Jaboticabal, SP, 1999 
Por outro lado, concordam com os de Dexter (1987) [2] que constatou, em solo com umidade suficiente, o crescimento radicular do milho com resistência à penetração do solo entre 4,0 e 5,0 Mpa. Gill e Bolt (1955) [7] explicam que o milho apresenta considerável potencial de crescimento radicular em razão da grande pressão axial da raiz, que varia de 0,95 a $2,49 \mathrm{MPa}$, isso convertido para resistência à penetração do solo equivaleria a 3,6 Mpa. Assim, os resultados desses autores evidenciam que, a compressão do solo em torno da semente não implica em prejuízos no desenvolvimento das raízes das plântulas até os limites testados.

Para profundidade de semeadura, observouse que não houve diferenças significativas (Tabela 1), resultado que está em desacordo com Yorinori et al. (1996) [17] que observaram efeito significativo da profundidade de semeadura na velocidade de emergência, sendo que a profundidade de $3 \mathrm{~cm}$ foi a que proporcionou maior percentagem e velocidade de emergência das plantas de milho-pipoca.

Por esses resultados pode-se inferir que a profundidade de semeadura entre 3 e $7 \mathrm{~cm}$ não apresenta restrições ao índice de velocidade de emergência do milho. Cabe destacar que há relato de que a melhor resposta para o índice de velocidade de emergência das plântulas em maiores profundidades de semeadura, possivelmente, devese ao efeito da temperatura do solo que, por sua vez, condicionará ambiente térmico favorável ao estabelecimento inicial da planta [12], portanto, há indicações de que seja possível a semeadura do milho até a $7 \mathrm{~cm}$ de profundidade, apesar de outros autores recomendarem a semeadura mais rasa, até $5 \mathrm{~cm} \mathrm{[5].} \mathrm{Cabe} \mathrm{salientar,} \mathrm{entretanto,} \mathrm{que} \mathrm{a}$ semeadura profunda (acima de $7 \mathrm{~cm}$ ) pode retardar a emergência das plântulas e em certos casos, impedí-la totalmente, pela incapacidade de as plântulas alongarem-se até alcançarem a luz [6].

$\mathrm{Em}$ função da relação positiva dos tratamentos no índice de velocidade de emergência, correlacionou-se 0 presente índice com o crescimento da planta, representado pela variável altura, no período compreendido entre os 25 e os 60 dias após a semeadura.

Pela Figura 3 se observa que o índice de velocidade de emergência apresentou, em geral, uma relação positiva com a altura da planta. Esses resultados vêm confirmar 0 efeito linear da compressão do solo no IVE mostrado anteriormente (Figura 1), que por sua vez levou ao maior crescimento da planta.

O fato da compressão do solo acelerar a emergência da plântula e, consequentemente, o maior crescimento inicial deve-se, possivelmente, à relação entre o aumento da densidade do solo e o maior tampão do solo para os nutrientes [13], ou seja, os autores explicam que à medida que baixa a concentração de nutrientes na solução do solo pela absorção da planta, ocorre rápida reposição do nível de nutrientes para a solução do solo, de forma que a planta jovem fica adequadamente suprida dos nutrientes, evitando assim o estresse nutricional.

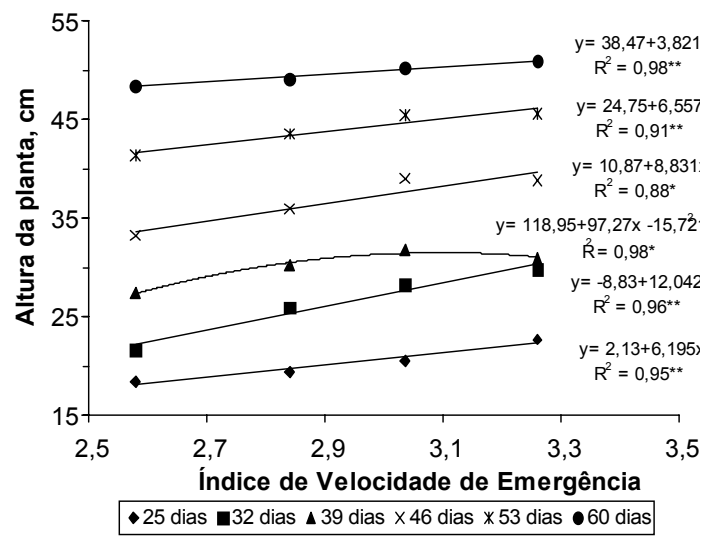

FIGURA 3 - Relação entre índice de velocidade de emergência e altura da planta de milho, no período de 25 a 60 dias após a semeadura, Jaboticabal, SP, 1999

Por outro lado a baixa compressão do solo levou a um baixo IVE, imprimindo menor crescimento inicial do milho. Esse resultado corrabora com os de Kooinstra et al. (1992) [9], que relataram que isso deve-se, possivelmente, ao menor contato raiz-solo, em razão da baixa densidade do solo em torno da semente reduzir o contato raiz-solo, com prejuízos no crescimento inicial da planta.

\section{CONCLUSÕES}

Nas condições em que foi conduzido o presente trabalho, pode-se concluir que a cultura do milho, para o estabelecimento inicial, responde de forma linear quanto ao índice de velocidade de emergência e a altura de planta à compressão do solo, variando de 5 a $15 \mathrm{kgf}$, na roda compactadora da semeadora, e não foram encontradas restrições para profundidade de semeadura dentro da faixa de 3 a $7 \mathrm{~cm}$.

\section{REFERÊNCIAS}

[1] COELHO, J. L. D. Critérios de seleção de máquinas e implementos agrícolas para a cultura do milho. In: FANCELLI, A. L. e DOURADO-NETO, D. (ed.) Tecnologia da produção de milho. Piracicaba: Publique, 1997. p. 1-9.

[2] DEXTER, A. R. Mechanics of roots growth. Plant Soil, Dordrecht, v.98,p. 303-312,1987.

[3] EMBRAPA. Relatório técnico anual do Centro Nacional de Pesquisa de Milho e Sorgo 1980-1984. Sete Lagoas: EMBRAPA/CNPMS, 1986. 190 p.

[4] EMBRAPA. Recomendações técnicas para o cultivo do milho. Brasília: EMBRAPA-SPI, 1993. 204 p.

[5] ÉLIARD, J. L. Manual geral de agricultura. Publicações Europa-América, 1979. 277 p.

[6] FORNASIERI FILHO, D. A cultura do milho. Jaboticabal: FUNEP, 1992. 273 p. 
[7] GILL, W. R.; BOLT, G. H. Pfeffer's studies of the root growth pressures exerted by plants. Journal, Madison, v.47, p. 166-168,1955.

[8] JOHNSON, W. H, HENRY, J. E. simulated row compactation on seedling emergence and soil deying nates. Transactions of the ASAE, v.7, n. 3, p. 252-255, 1964.

[9] KOOINSTRA, M. J.; SCHOONDERBEEK, D.; BOONE, F. R.; VEEN, B. W.; NOORDWIJK, M. Van Root-soil contact of maize as measured by a thin-section technique. II-Effects of soil compaction. Plant Soil, Dordrecht, v. 139, p. 119-129, 1992.

[10]LARSON, W. E. Soil parameters for evaluating tillage needs and operations. Soil Science American Proceedings, v.28, p. 118-122, 1964.

[11]NAKAGAWA, J. Testes de vigor baseados na avaliação de plântulas. In: VIEIRA, R. D.; CARVALHO, N. M. (Ed.) Testes de vigor em sementes. Jaboticabal: FUNEP, 1994. p. 49-86.

[12] ORTOLANI, A. F.; BANZATO, D. A.; BORTOLI, N. M. Influência da profundidade e da compactação do solo, na emergência e desenvolvimento do sorgo granífero (Sorghum bicolor L. Moench). In: CONGRESSO BRASILEIRO DE ENGENHARIA AGRÍCOLA 15., 1986, Botucatu. Anais. Botucatu: Sociedade Brasileira de Engenharia Agrícola, 1986. p. 24-32.
[13] SILBERBUCCH, M.; HALLMARK, W. B.; BARBER, S. A. Simulation of effects of soil bulk density and $P$ addition on $\mathrm{K}$ uptake of soybean. Comm. Soil Science Plant Anal, New York, v.14, p.287-296, 1983. 673 p.

[14]SMUCKER, A. J. M.; ERICKSON, A. E. Tillage and compactive modifications of gaseous flow and soil aeration. In: LARSON, W. E.; BLAKE, G. R.; ALLMARAS, R. R.; VOORHEES, W. B.; GUPTA, S.C. (eds.) Mechanics related process in structured agricultural soils. NATO applied science, The Netherlands, Kluwer Academic Publishrs, 1989. v. 172, p. 205-221.

[15]VEEN, B W W BOONE, F. R . The influence of mechanical resistance and soil water on the growth of seminal roots of maize. Soil Tillering Research, Amesterdam, v.16, p. 219-226, 1990.

[16]VITTI, G. C.; FAVARIN, J. L. Nutrição e manejo químico do solo para a cultura do milho. In: FANCELLI, A. L.; DOURADO-NETO, D. (ed.) Tecnologia da produção de milho. Piracicaba: Publique, 1997. p. 104-120.

[17] YORINORI, N. A.; SADA, S. Y.; PISSAIA, A. Efeito da profundidade de semeadura e do envelhecimento precoce de sementes de milho-pipoca (Zea mays L.) sobre a emergência e vigor de plantas. Revista do Setor de Ciências Agrárias, Curitiba, v.15, n.2, p. 173178, 1996.

Recebido para publicação em 27 ABR 2000 [SA 022/2000] Aceito para publicação em 28 MAR 2001 